ARTIFICIAL SATELLITES, Vol. 49, No. 4 - 2014

DOI: 10.2478/arsa-2014-0016

\title{
ANALYZING THE IMPACT OF DIFFERENT PCV CALIBRATION MODELS ON HEIGHT DETERMINATION USING GPS/GLONASS OBSERVATIONS FROM ASG-EUPOS NETWORK
}

\author{
Karol Dawidowicz \\ University of Warmia and Mazury in Olsztyn, Institute of Geodesy \\ e-mail: karol.dawidowicz@uwm.edu.pl
}

\begin{abstract}
The integration of GPS with GLONASS is very important in satellite-based positioning because it can clearly improve reliability and availability. However, unlike GPS, GLONASS satellites transmit signals at different frequencies. This results in significant difficulties in modeling and ambiguity resolution for integrated GNSS positioning. There are also some difficulties related to the antenna Phase Center Variations (PCV) problem because, as is well known, the PCV is dependent on the received signal frequency dependent. Thus, processing simultaneous observations from different positioning systems, e.g. GPS and GLONASS, we can expect complications resulting from the different structure of signals and differences in satellite constellations.

The ASG-EUPOS multifunctional system for precise satellite positioning is a part of the EUPOS project involving countries of Central and Eastern Europe. The number of its users is increasing rapidly. Currently 31 of 101 reference stations are equipped with GPS/GLONASS receivers and the number is still increasing. The aim of this paper is to study the height solution differences caused by using different PCV calibration models in integrated GPS/GLONASS observation processing. Studies were conducted based on the datasets from the ASG-EUPOS network. Since the study was intended to evaluate the impact on height determination from the users' point of view, a so-called "commercial" software was chosen for post-processing. The analysis was done in a baseline mode: 3 days of GNSS data collected with three different receivers and antennas were used. For the purposes of research the daily observations were divided into different sessions with a session length of one hour. The results show that switching between relative and absolute PCV models may cause an obvious effect on height determination. This issue is particularly important when mixed GPS/GLONASS observations are post-processed.
\end{abstract}

Keywords: PCV, GPS, GLONASS, height determination, ASG-EUPOS

\section{INTRODUCTION}

The Global Positioning System (GPS) now plays a major role in both surveying and navigation. For such satellite-based positioning systems, it is well known that the accuracy, availability and reliability of the positioning results are very dependent on the number of satellites being tracked. However, in some situations, such as in urban areas, the number of visible satellites may not be sufficient to perform the positioning. One possible strategy for increasing the availability of satellites is to integrate GPS with another GNSS system, such as the Russian GLObal NAvigation Satellite Systems (GLONASS). The GLONASS 
constellation has recently been greatly improved. Since November 2011, there have been 24 operational GLONASS satellites.

Like GPS, GLONASS has a great potential for precise navigation and geodetic applications (Zarraoa et al., 1998). This potential was demonstrated, in part, during the International GLONASS Experiment-IGEX98 (Slater et al., 1998; Willis et al., 1999) and is being continuously developed (Bruyninx, 2007; Cai and Gao, 2007; Dawidowicz and Krzan, 2014; Dodson et al., 1999).

In both the GPS and GLONASS systems, two fundamental measurements can be decoded from the satellite signals: the pseudo-ranges and the carrier phases. Since, as is well known, carrier phase measurements are much more precise than the pseudo-ranges, they are the primary measurements for precise positioning. However, the carrier phase measurements are "ambiguous". In GPS positioning, the integer carrier phase ambiguities can be resolved in the relative mode using double-differencing procedures (Hofmann-Wellenhof et al., 2008). This principle can also be applied to integrated GPS and GLONASS positioning. However, in combined GPS and GLONASS data processing, the tasks of defining the mathematical and stochastic models are difficult to accomplish. For example, due to the different frequencies of GLONASS satellites, standard double-differencing procedures cannot cancel receiver clock errors. During the last decade, much effort has been made to integrate signals from the combined GPS and GLONASS constellation. A variety of mathematical and stochastic modeling and ambiguity resolution procedures have been proposed in literatures (Habrich et al., 1999; Han et al., 1999; Slater et al., 1998; Wang et al., 2000; Zhang and Liu, 2002).

Several problems in integrated GPS/GLONASS observation processing can also be seen in the context of the antenna phase center variations. Antenna phase variation is a variation of the antenna phase center beyond the antenna offset. Different antenna types exhibit different phase variations (Mader, 1999). The GPS antenna phase center shift in position depends on the direction of the incident signal (elevation angle and azimuth to the satellite) and on the intensity of this signal. This shift is expressed by mean Phase Center Offsets (PCO) and by so-called "phase center variations" (PCV) for L1 and L2 frequencies (Schupler and Clark, 2001; Wu et al., 1993). Lack of determining the exact PCV is a basic source of errors when different types of antennas are mixed. Thus, the PCV problem is significant for applications requiring high precision. Reviews of the antenna PCV problem are widely available, e.g. in (Braun et al., 1993; Dawidowicz and Świątek, 2008; Dawidowicz, 2012; Geiger, 1998; Rocken, 1992; Schmid et al., 2005; Schupler and Clark, 1991; Völksen, 2006).

Spatial relations between Antenna Reference Point (ARP), PCO and PCV points are determined by the calibration process and antenna Phase Center Corrections (PCC) models can then be created. The antenna calibration can be performed in various ways (Falko et al., 1998; Görres et al., 2006; Mader, 1999; Rothacher, 2001; Schmid et al., 2005; Schmitz et al., 2002; Zeimetz and Kuhlman, 2008).

Generally, at present there are two GNSS antenna models. One is the relative IGS antenna phase center correction model from relative field calibration; the other is the absolute IGS antenna phase center correction model converted from relative (all the relative antenna offsets and phase center variations that the National Geodetic Survey has computed have been added to the absolute values for AOAD/M_T antenna) or from an absolute field or chamber calibration. For GNSS satellites, there may be two solutions: the standard IGS antenna offset model and the absolute antenna phase center correction model.

On 17 April, 2011 the IGS introduced a new set of antenna calibrations (igs08.atx). This new set takes into account the new robot calibrations that have been measured since the release of the igs05.atx (Baire et al., 2011). However, in igs08.atx there are still models from 
different calibrations procedures as well as a large number of antennas without the corrections for GLONASS signals.

The GLONASS PCV calibration differs compared to GPS as a result of the different frequencies of individual GLONASSS satellites. The satellite constellation was not initially sufficient to perform a PCV calibration. In the beginning of the absolute field calibration, the robot adopted for GLONASS signals was stopped after three complete days without sufficient coverage of the antenna hemisphere. Actually, calibrations for different GNSS antenna types are quite possible. Although the absolute robot calibration estimated PCV from the mixture of observed GLONASS frequencies - the calibration are satellite constellation-dependent and are not expected to be as accurate as for GPS (Dach et al., 2010; Wubbena et al., 2006).

Another PCV modeling concept has been developed which allows frequency-dependent GLONASS PCV to be determined. The fundamental assumption of this concept is the linearity of PCV changes for GPS/GLONASS and GLONASS/GLONASS frequencies. A detailed description of this method can be found in (Wubbena et al., 2006). In this approach, in IGS ANTEX files, PCCs are given only for the channel number $k=0$. Geo++, which calibrates antennas, first computes the so-called Delta PCVs, which are then multiplied by the frequency difference between GLONASS and GPS and added to GPS PCVs. This procedure obtains GLONASS PCVs for any channel number $k$.

Ultimately, it is common to use GPS PCV for the correction of GLONASS PCV due to a lack of better information.

The aim of this paper was to study the height differences when different calibration models are used in GPS/GLONASS processing using datasets from the ASG-EUPOS network. There is a worldwide trend towards the establishment of continuously operating reference stations (CORS) which allow a user to incorporate reference network data into a local or regional network solution at little or no extra cost. The ASG-EUPOS - the Polish GNSS Ground Based Augmentation System is an example of such a network (Bosy et al., 2008; Figurski et al., 2009). ASG-EUPOS offers three real-time and two post-processing services. Generally, for users who demand the highest precision results, the post-processing services are provided (POZGEO or POZGEO D). In the POZGEO service, post-processing of the uploaded observation files and determination of the point's coordinates are made independently referring to the six nearest stations. ASG-EUPOS Automatic Post-Processing Software (APPS) uses algorithms based on Schreiber's type sets of carrier-phase differences (Kadaj, 2010). Because of the relatively long distances between stations $(\sim 70 \mathrm{~km})$ and the automation of the calculation process, obtaining high accuracy requires a long observation period. The POZGEO service uses absolute antenna PCV models.

The POZGEO D service is a means for more advanced users who download observation files from ASG-EUPOS reference stations and process data using commercial post-processing software. The POZGEO D service makes it possible to obtain higher accuracy from shorter observational sessions, although it requires some knowledge of GNSS observation processing. Generally, in commercial post-processing software there is no information on what type of PCV model for receivers or satellites antennas is used.

Understanding the PCV problem is essential when the antenna at the reference station differs from that of the user point. Additionally, in processing simultaneous observations from different positioning systems, e.g. GPS and GLONASS, we can expect further complications resulting from the different structure of signals and differences in satellite constellations (e.g. each GLONASS satellite completes an orbit in approximately 11 hours 15 minutes while the GPS satellite takes approximately 11 hours 58 minutes). Another potential difficulty is the fact that different GLONASS satellites transmit signals on different frequencies. A review of 
the GPS/GLONASS observations processing problem can be found in (Bruyninx, 2007; Dodson et al., 1999; Wang, 1999; Weber et al., 2005). In the author's opinion however, there is lack of similar studies of the PCV problem. Because ASG-EUPOS GPS-only receivers are currently being systematically replaced by receivers able to receive signals from different Global Navigation Satellite Systems, this issue is of particular interest.

\section{RESEARCH AREA}

ASG-EUPOS (Fig. 1) is a Polish GNSS Ground Based Augmentation System. The name ASG-EUPOS stands for Active Geodetic Network European Position Determination System. Currently, (08.2014) ASG-EUPOS consists of 101 stations located with Poland (31 equipped in GPS/GLONASS receivers) and 23 foreign stations (20 equipped with GPS/GLONASS receivers).

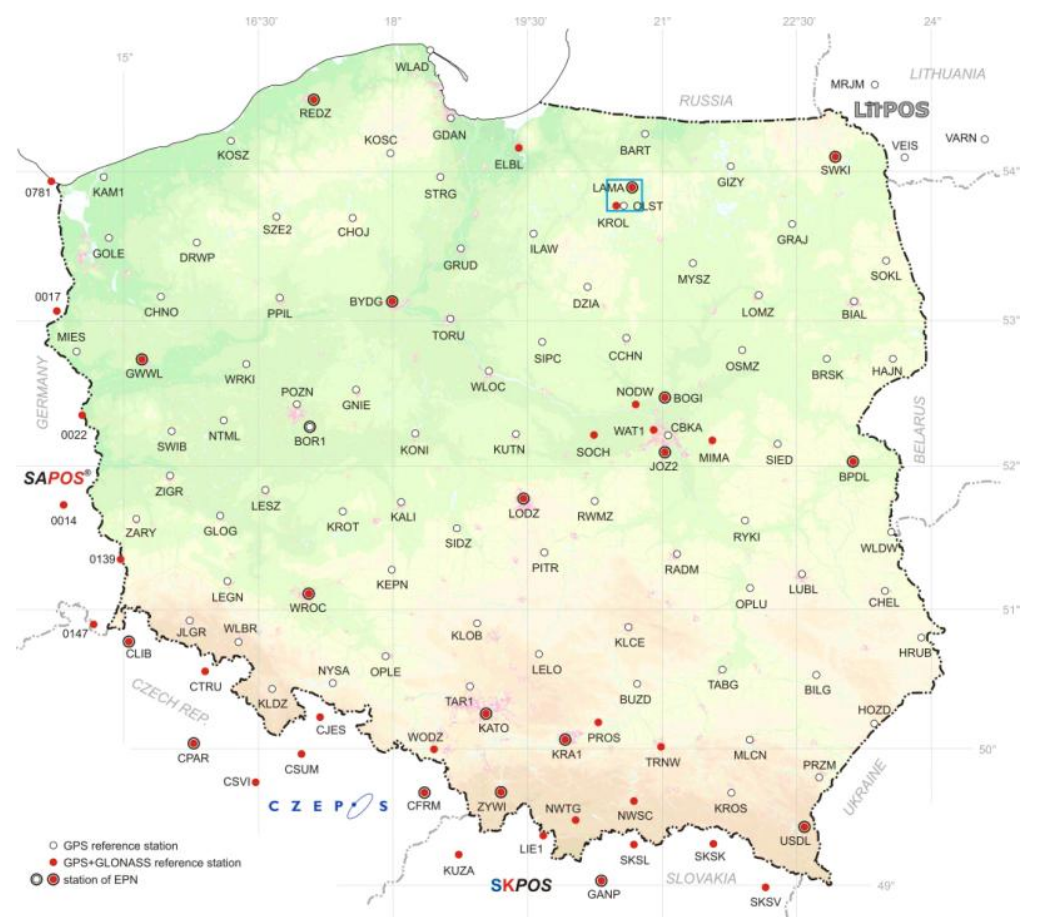

Fig.1. Location of the test areas in the ASG-EUPOS network.

(map: www.asgeupos.pl)

\section{RESEARCH STRATEGY}

For the analysis two ASG-EUPOS stations equipped with GPS/GLONASS receivers were selected. Additionally, three 24-hour measurement sessions were conducted on a point with a TPSHIPER_PLUS antenna (Table 1). 
Table 1. Hardware on selected points in baseline mode.

\begin{tabular}{|c|c|c|c|}
\hline Point name & LAMA & KROL & 0001 \\
\hline Antenna type & LEIAT 504GG LEIS & $\begin{array}{c}\text { JAVAD RINGANT } \\
\text { G3T }\end{array}$ & TPSHIPER_PLUS \\
\hline Figure of antenna & & & \\
& & & \\
\hline Receiver type & GRX1200GG+GNSS & $\begin{array}{c}\text { LAVAD TR_G3TH } \\
\text { SIGMA }\end{array}$ & Hiper Pro \\
\hline
\end{tabular}

(figures of antenna source: http://www.ngs.noaa.gov/ANTCAL/)

A comparison of the antenna phase characteristics for L1 and L2 frequency is shown in Fig. 2.
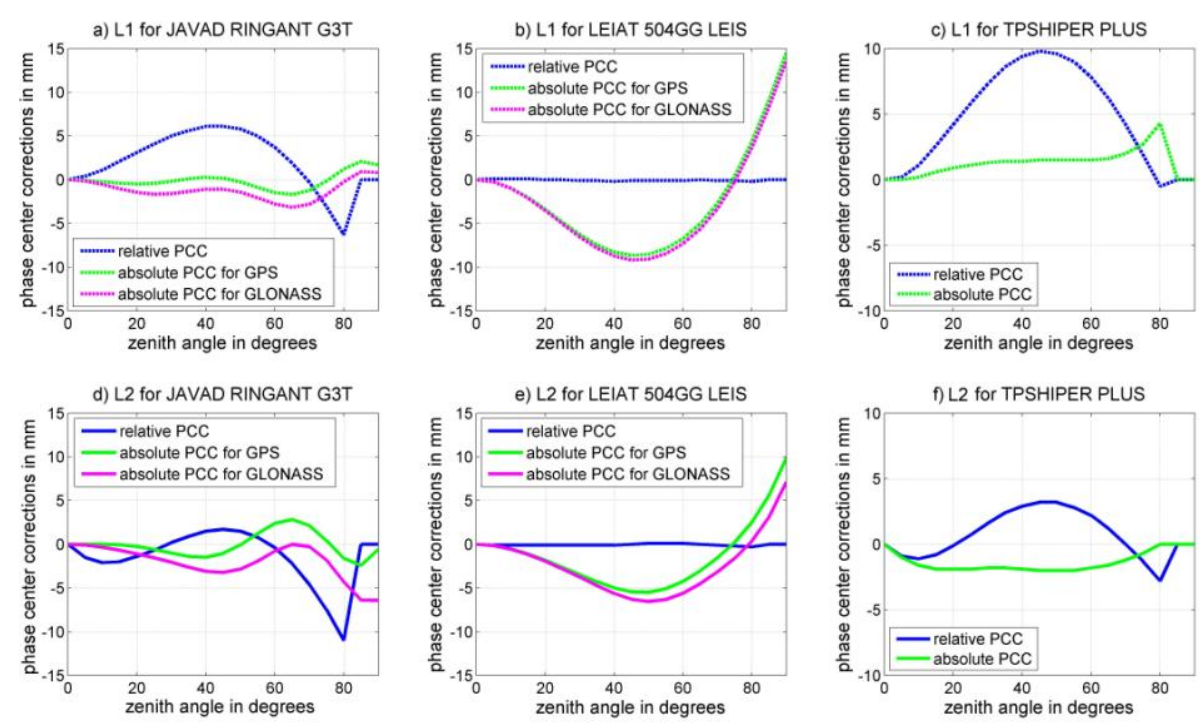

Fig. 2. IGS zenith angle dependent phase center variations: a, d) JAVAD RINGANT G3T antenna; b, e) LEIAT 504GG LEIS antenna; c, f) TPSHIPER_PLUS antenna (source: http://www.ngs.noaa.gov/ANTCAL/)

It is clear that the selected antennas are characterized by differences between their phase characteristics. Generally, the greatest difference was observed for medium zenith angles (from $30^{\circ}$ to $60^{\circ}$ ). These differences are also visible in comparing PCV characteristics for the same antenna, obtained from different calibration procedures (especially between relative and absolute calibration results) - the maximum differences for the same frequency reach $10 \mathrm{~mm}$. In comparing absolute elevation-dependent PCV for GPS and GLONASS signals, there are only small differences at a level of 2-3 $\mathrm{mm}$.

In addition to the above figures, the L1 and L2 offsets (PCO) for the antennas used are presented in Table 2. Clear differences were also found between the results of the relative and two other calibration sets. 
Table 2. The locations of MPC over ARP for antennas used in measurements.

\begin{tabular}{|c|c|c|c|c|c|c|}
\hline \multirow{2}{*}{ Calibration model } & \multicolumn{7}{|c|}{ Locations of MPC over ARP [mm] } \\
\cline { 2 - 7 } & \multicolumn{2}{|c|}{ LEIAT504GG } & JAV_GRANT-G3T & TPSHIPER_PLUS \\
\cline { 2 - 7 } & L1 & L2 & L1 & L2 & L1 & L2 \\
\hline Relative & 107.4 & 126.2 & 69.4 & 60.6 & 105.9 & 97.1 \\
\hline Absolute GPS-only & 89.6 & 119.6 & 50.3 & 46.8 & 87.1 & 89.2 \\
\hline Absolute GPS/GLONASS & 89.6 & 119.6 & 50.3 & 46.8 & - & - \\
\hline
\end{tabular}

Because the study was intended to evaluate the impact on height determination from the end users' point of view, the correction models and processing parameters were the same as others would have used.

The following GNSS parameters were set for all sessions: sampling interval $1 \mathrm{~s}$, satellite mask elevation angle $10^{\circ}$.

Three 24-hour measurement sessions were divided into some one-hour sessions and processed in a single-baseline mode using Topcon Tools software. In such short sessions, height changes can be visualized as a result of changes in the satellite' constellation above the measured point.

The processing was done in three main variants (STRATEGIES):

- using the relative (relative) IGS models;

- using the GPS-only absolute (absolute) IGS models;

- $\quad$ using the GPS/GLONASS absolute (absolute+) IGS models.

Since there are only relative and absolute GPS-only antenna PCV models available for some antennas (TPSHIPER_PLUS and ASH701945C_M SNOW), the third strategy employs a mixed absolute+/absolute strategy.

In baseline mode, each "strategy' was processed using L1-only observations (simulating measurements done with an L1 receiver) and using the so-called "ionosphere-free linear combination" - L3 (double-frequency observation variant). Using the L3 combination in our processing causes the differences in antenna PCV of both frequencies to appear in the final results.

It is well known that over very short baselines, higher precision results can be obtained using single frequency (L1) differential GPS data instead of using dual frequency data. This has two reasons. First, ionospheric effects at the two ends of a short baseline are very similar and can be canceled out in differential processing. Second, the observational noise of the L3 linear combination is larger by a factor of $\sim 3$ than that for L1 only observations and L3 combinations also considerably amplify systematic effects due to multipath, antenna phase center offsets and variations, etc (Schaer, 1999). Generally, single-frequency observations (L1) are used for processing baselines no longer than $10-15 \mathrm{~km}$, where the ionospheric delays cancel out during differencing of the observations. The lower cost L1 GPS receivers can provide more precise surveying than more expensive dual frequency receivers over baselines up to $30 \mathrm{~km}$ in length. However, this approach requires the ionospheric delay to be modeled with a high level of precision. Single frequency receivers using such a model can provide better GPS surveying results than dual frequency receivers, even during solar maximum conditions. Generally, when processing baselines longer than 10-15 km, the ionosphere model should be taken into account in order to reduce the residual delays. 
Because in our analysis the results of processing the same observations in two variants (using absolute or absolute + and relative field calibration models) were compared, it can be assumed that the influence of ionosphere, troposphere or multipath is the same for the same observations.

In a network mode, we allowed Topcon Tools to automatically select the processing frequency. In Topcon Tools, automatic selection of processing frequency is as follows:

- 0-10 $\mathrm{km}$ baseline processing is L1 and L2,

- 10-30 km baseline processing is L1\&L2c (ionosphere-free combination),

- 30-400 km baseline processing is wide-lane.

All other processing options (tropospheric model, orbits, etc.) were identical in all runs. The results of calculation and their discussion are provided below.

\section{ANALYSIS OF RESULTS}

The paper presents the height differences obtained in GPS/GLONASS observation processing when different calibration models are used.

The analysis was done using 3 days of GNSS data, collected with a Topcon Hiper Pro receiver, divided by one-hour observation sessions. As a reference, two ASG-EUPOS stations (LAMA and KROL) were selected.

The results obtained with the LEIAT504GG and TPSHIPER_PLUS antennas (height differences for the previously mentioned processing strategies, on the TPSHIPER_PLUS antenna point) are presented in Figure 3 and in Table 3. The figures show the height differences obtained from the processing of GNSS observations using relative and absolute or relative and absolute+ calibration results. Table 3 shows a summary of the height differences obtained for the baseline. 
a) L1 GPS

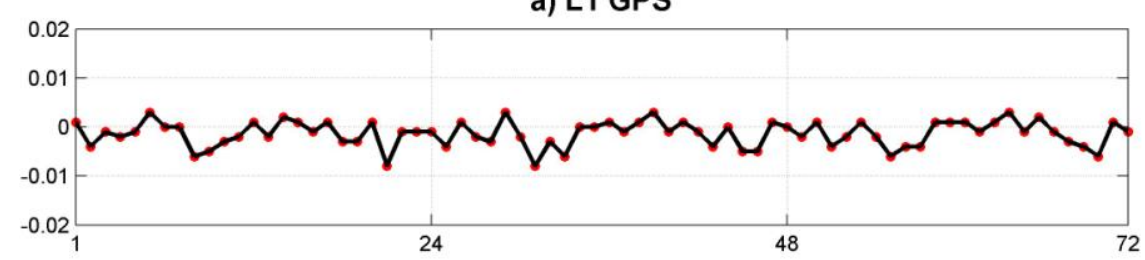

b) L1 GPS+GLONASS

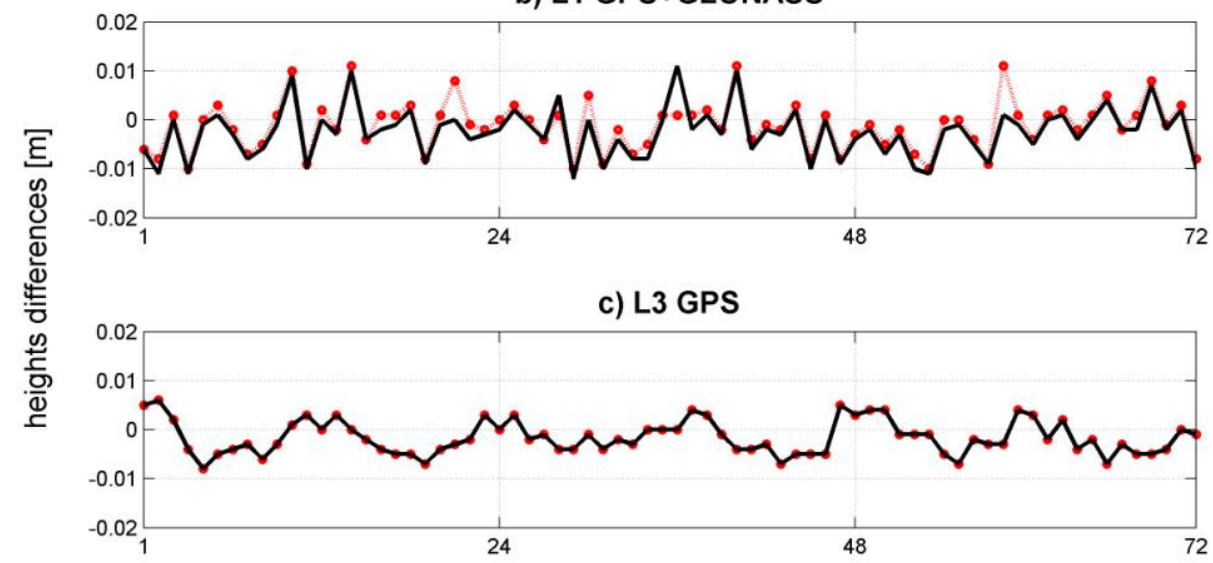

d) L3 GPS+GLONASS

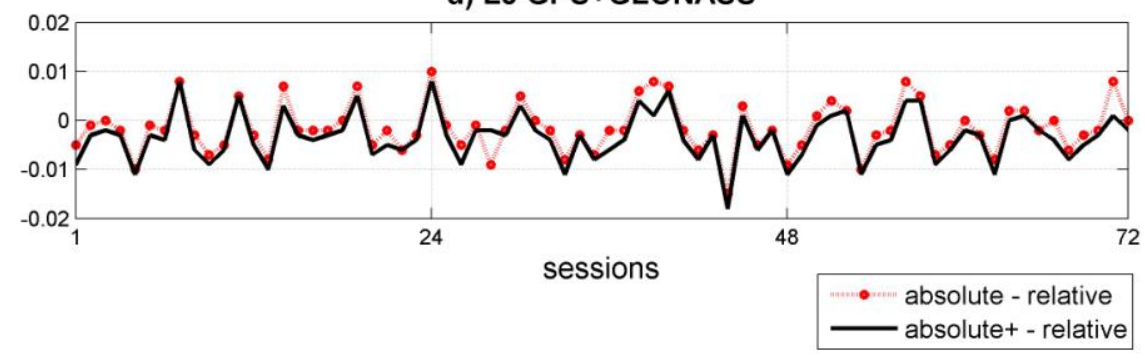

Fig. 3. The results of processing observations for baseline LAMA - 0001: a) L1 - GPS-only solutions, b) L1 - GPS/GLONASS solutions, c) L3 - GPS-only solutions, d) L3 GPS/GLONASS solutions

Table 3. Summary of height differences obtained for baseline LAMA- $0001[\mathrm{~cm}]$.

\begin{tabular}{|c|c|c|c|c|c|c|}
\hline \multirow{2}{*}{ Post-processing variants } & \multicolumn{3}{|c|}{ Height differences for GPS } & \multicolumn{3}{c|}{$\begin{array}{c}\text { Height differences for } \\
\text { SPS/GLONASS solutions }\end{array}$} \\
\cline { 2 - 7 } & Max. & Min. & Average & Max. & Min. & Aver. \\
\hline L1 absolute - relative & 0.3 & -0.8 & -0.13 & 1.1 & -1.0 & -0.11 \\
\hline L1 absolute+ - relative & 0.3 & -0.8 & -0.13 & 1.1 & -1.2 & -0.25 \\
\hline L3 absolute - relative & 0.6 & -0.8 & -0.16 & 0.8 & -1.5 & -0.15 \\
\hline L3 absolute+ - relative & 0.06 & -0.8 & -0.16 & 0.8 & -1.8 & -0.33 \\
\hline
\end{tabular}

In analyzing the results obtained for the baseline with LEIAT504GG and TPSHIPER_PLUS antennas, it can be seen that the height differences for the GPS-only solutions are within 0.8 $\mathrm{cm}$ (L1 and L3 variant). The average height difference for the two presented variants is below $2 \mathrm{~mm}$ (Table 3). As expected, the differences from absolute - relative and absolute+ relative are identical (when GPS-only observations are used corrections for GLONASS satellites not affect the results).

Larger differences were obtained for processing using GPS/GLONASS observations. Comparing the height differences obtained using the absolute and relative calibrations models, it is clear that for some sessions its size reaches $2 \mathrm{~cm}$. For the variant with absolute+ 
and relative calibration models, the maximum height difference is $2-3 \mathrm{~mm}$ larger. In general, using an absolute+ model induced the generation of a 1-2 mm higher elevation of 0001 point in comparison to calculations using the absolute model. However, there are some sessions when the obtained heights differ significantly more (up to $10 \mathrm{~mm}$ ).

In analyzing the summary of height differences (Table 3), it is clear that the effect of switching between calibration models is more evident in the GPS/GLONASS observation processing variants. This is especially true when we compare maximum and minimum height differences.

The results for the baseline with the JAV_GRANT-G3T and TPSHIPER_PLUS antennas are presented below (Fig. 4 and Table 4).

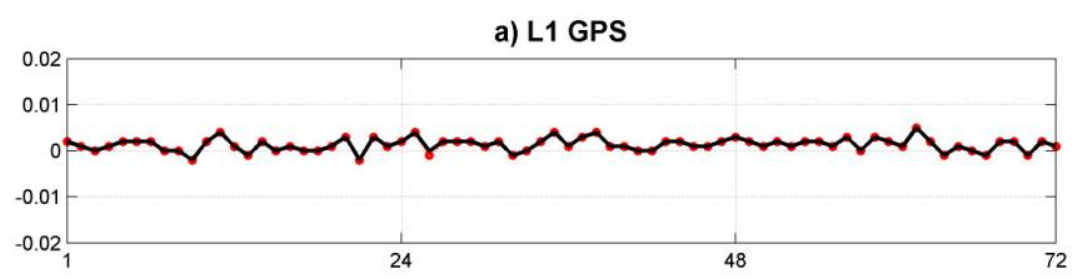

b) L1 GPS+GLONASS

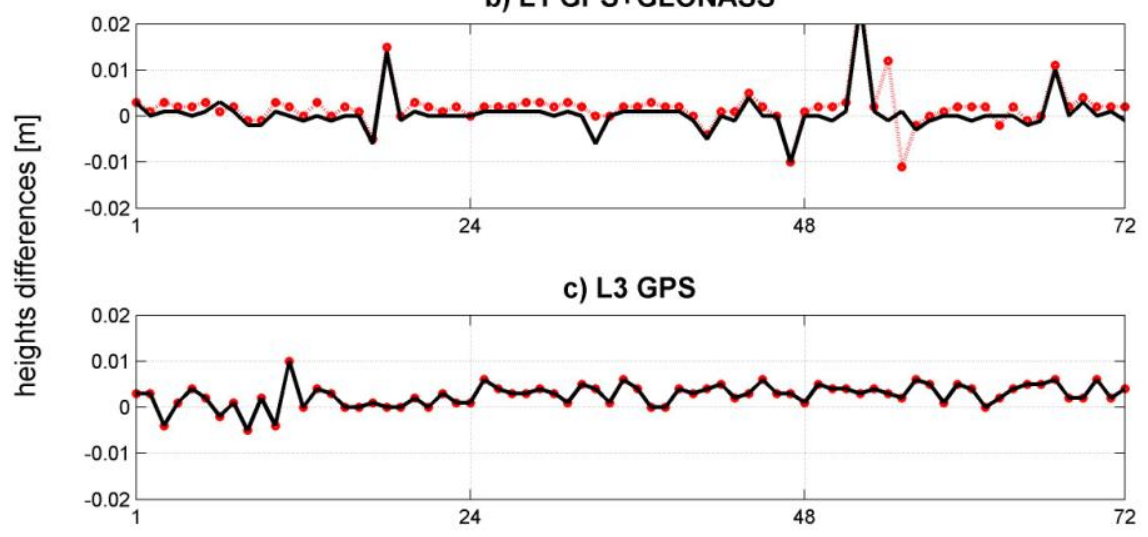

d) L3 GPS+GLONASS

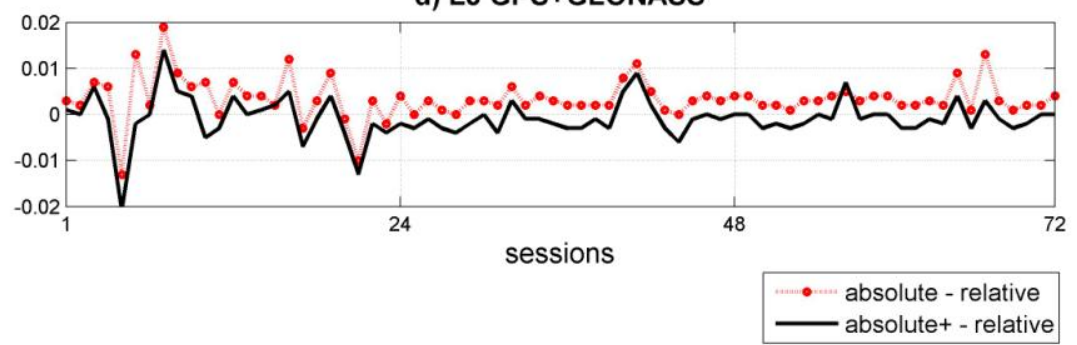

Fig. 4. The results of processing observations for baseline KROL - 0001: a) L1 - GPS-only solutions, b) L1 - GPS/GLONASS solutions, c) L3 - GPS-only solutions, d) L3 GPS/GLONASS solutions

Table 4 shows a summary of the height differences obtained for the baseline. 
Table 4. Summary of height differences obtained for baseline KROL-0001[cm].

\begin{tabular}{|c|c|c|c|c|c|c|}
\hline \multirow{2}{*}{ Post-processing variants } & \multicolumn{3}{|c|}{ Height differences for GPS } & \multicolumn{3}{c|}{$\begin{array}{c}\text { Height differences for } \\
\text { GPS/GLONASS solutions }\end{array}$} \\
\cline { 2 - 7 } & Max. & Min. & Average & Max. & Min. & Aver. \\
\hline L1 absolute - relative & 0.5 & -0.2 & 0.13 & 2.6 & -1.1 & 0.18 \\
\hline L1 absolute+ - relative & 0.5 & -0.2 & 0.13 & 2.4 & -1.0 & 0.05 \\
\hline L3 absolute - relative & 0.6 & -0.5 & 0.26 & 1.9 & -1.3 & 0.34 \\
\hline L3 absolute+ - relative & 0.6 & -0.5 & 0.26 & 1.4 & -2.1 & 0.08 \\
\hline
\end{tabular}

In analyzing the results obtained for the baseline with JAV_GRANT-G3T and TPSHIPER_PLUS antennas, it can be seen that the height differences for the GPS-only solutions are within $0.5 \mathrm{~cm}$ (L1 variants) and $0.6 \mathrm{~cm}$ (L3 variants). Comparing the average height difference (Table 4), it is clear that it is twice as large for the L3 variant.

Significantly greater differences were obtained for processing using GPS/GLONASS observations. The height differences obtained for the solutions using the absolute and relative calibrations models for some sessions reach $2.6 \mathrm{~cm}$. For the variant with absolute+ and relative calibration models, the maximum height difference reaches $2.4 \mathrm{~cm}$.

Generally, using the absolute+ model induced the generation of 1-3 mm higher elevation of 0001 point in comparison to calculations using the absolute model. There are also some sessions where the obtained height differs significantly up to $10 \mathrm{~mm}$. In this case, the effect of switching between calibration models is also more evident in the GPS/GLONASS observation processing.

However, it is worth mentioning that although the obtained average height differences are small $(1-3 \mathrm{~mm})$ and generally could be ignored in most of the surveying tasks, for some onehour sessions the differences exceed $2 \mathrm{~cm}$ and these jumps seem relevant for many high accuracy applications.

\section{CONCLUSIONS}

In this study, the height differences caused by using different calibration models in GPS-only and GPS/GLONASS observations processing based on the datasets from the ASG-EUPOS network were compared. The analysis was done in baseline mode: 3 days of GNSS data were used, which were collected with three different receivers and antennas, divided by one-hour sessions. Since the study was intended to evaluate the impact on height determination from the end users' point of view, a so-called "commercial" software was chosen for postprocessing.

The advantage of the absolute approach is clear. Only coordinates that reflect physics can be used in combinations with other space techniques (e.g. SLR, VLBI). Unfortunately, to date not all antennas have models using absolute calibration. Additionally, when simultaneously processing observations from GPS and GLONASS systems, some complications can be expected resulting from the different structure of signals, differences in satellite constellations and difficulties in GLONASS PCV modeling.

The update of receiver antenna calibrations from relative to absolute in baseline mode (using GPS-only observations) induces a jump in height differences up to $0.8 \mathrm{~cm}$. For GPS/GLONASS observations, the differences are clearly larger (up to $2.6 \mathrm{~cm}$ ). Although the average height difference for the two presented baselines are relatively small $(1-3 \mathrm{~mm})$ the previously mentioned jumps may be relevant for many high accuracy applications.

In addition there was a clear occurrence of large jumps in GPS/GLONASS results (particularly for KROL - 0001 baseline). This may result from some problems associated 
with the combined processing of GPS and GLONASS observations, e.g. due to the different signal frequencies for the different GLONASS satellites, the commonly used doubledifferencing procedure for carrier phase data processing cannot be implemented in its simplest form. In the author's opinion, this problem needs further to study.

\section{REFERENCES}

Baire O., Pottiaux E., Bruyninx C., Defraigne P., Legrand J., Bergoet N. (2011). Comparison of Receiver Antenna Calibration Models used in the EPN, http://www.euref.eu/symposia/2011Chisinau/Symposium2011-Chisinau.html.

Bosy J., Oruba A., Graszka W., Leończyk M., Ryczywolski M. (2008). ASG-EUPOS densification of EUREF Permanent Network on the territory of Poland, Reports on Geodesy, No. 2 (85), 105-112.

Braun J., Rocken C., Meertens C.M., Johanson J. (1993). GPS antenna mixing and phase center corrections, Eos Trans. AGU, Fall Meeting Supplement, 197.

Bruyninx C. (2007). Comparing GPS-only with GPS+GLONASS positioning in a regional permanent GNSS network, GPS Solutions, Vol. 11(2), 97-106.

Cai C., Gao Y. (2007). Precise Point Positioning using combined GPS and GLONASS observations, Journal of Global Positioning Systems, Vol. 6(1), 13-22.

Dach R., Schmid R., Schmitz M., Thaller D., Schaer S., Lutz S., Steigenberger P., Wubbena G., Beutler G. (2010). Improved antenna phase center models for GLONASS, GPS Solutions, Vol. 15, 49-65.

Dawidowicz K., Świątek K. (2008). Some aspects of GPS observation elaboration for heights appointment requirements, The 7th International Conference ENVIROMENTAL ENGINEERING, Selected papers, Vol. III, 1300-1304.

Dawidowicz K. (2012). Antenna calibration models in height determinations in ASGEUPOS’ POZGEO-D service - a case study, Artificial Satellites, Vol. 47(4), 155-167.

Dawidowicz K., Krzan G. (2014). Coordinate estimation accuracy of static Precise Point Positioning using on-line PPP service, a case study, Acta Geodaetica et Geophysica, Vol. $49,37-55$.

Dodson A., Moore T., Baker D.F., Swann J.W. (1999). Hybrid GPS + GLONASS, GPS Solutions, Vol. 3 (1), 32-41.

Falko M., Seeber G., Völksen Ch., Wübbena G., Schmitz M. (1998). Results of Absolute Field Calibration of GPS Antenna PCV, ION GPS-98; Proceedings of the 11th International Technical Meeting of the Satellite Division of the Institute of Navigation, Nashville, TN; UNITED STATES; 15-18 Sept., 31-38.

Figurski M., Kamiński P., Kroszczyński K., Szafranek K. (2009). ASG-EUPOS monitoring with reference to EPN, Artificial Satellites, Vol. 44, 85-94.

Geiger A. (1998). Modeling of Phase Center Variation and its Influence on GPS Positioning, GPS-Techniques Applied to Geodesy and Surveying: Proceedings of the International GPS-Workshop Darmstadt, April 10 to 13, Editor: Erwin Groten, Robert Strauß, Lecture Notes in Earth Sciences, Vol. 19, 210-222.

Görres B., Campbell M., Becker M., Siemes M. (2006). Absolute calibration of GPS antennas: Laboratory results and comparison with field and robot techniques, GPS solutions, Vol. 10, 136-145. 
Habrich H., Beutler G., Gurtner W., Rothacher M. (1999). Double difference ambiguity resolution for GLONASS/GPS carrier phase, 12th Int. Tech. Meeting of the Satellite Division of the U.S. Inst. of Navigation GPS ION'99, Nashville, Tennessee, 14-17 Sept., 1609-1618.

Han S., Dai L., Rizos C. (1999). A new data processing strategy for combined GPS/GLONASS carrier phase-based positioning, Proc. ION GPS-99, 1999 gmat.unsw.edu.au.

Hofmann-Wellenhof B., Lichtenegger H., Wasle E. (2008). GNSS - Global Navigation Satellite Systems, Springer-Verlag Wien, Austria, 516 pages.

Kadaj R. (2010). Application of Schreiber's type difference observation system for elaboration of a session of static GPS measurements, Biuletyn Wojskowej Akademi Technicznej, Vol. LIX, No 2 (658), 85-106.

Mader G.L. (1999). GPS Antenna Calibration at the National Geodetic Survey, GPS Solutions, Vol. 3(1): 50-58.

Rothacher M. (2001). Comparison of Absolute and Relative Antenna Phase Center Variations, GPS Solutions, Vol. 4: 55-60.

Rocken C. (1992). GPS antenna mixing problems. UNAVACO Memo, November 12.

Schaer, S. (1999). Mapping and Predicting the Earth's Ionosphere Using the Global Positioning System. Ph.D. dissertation., Astronomical Institute University of Bern, Bern. 205 pages.

Schmid R., Rothacher M., Thaller D., Steigenberger P. (2005). Absolute phase center corrections of satellite and receiver antennas, GPS Solutions, Vol. 9(4), 283-293.

Schmid R., Steingerberg P., Rotchacher M. (2005). Benefits from absolute GPS antenna phase center modeling, Advances in GPS Data Processing and Modelling, London 9-10 November, www.espace-tum.de/mediadb/15354/15355/Vortrag_London.pdf.

Schmitz M., Wübbena G., Boettcher G. (2002). Tests of phase center variations of various GPS antennas, and some results, GPS Solutions, Vol 6: 18-27.

Schupler B.R., Clark T.A. (1991). How Different Antennas Affect the GPS Observable, GPS World, No. 2(10): 32-36.

Schupler B.R., Clark T.A. (2001). Characterizing the Behavior of Geodetic GPS Antennas, GPS World, No. 12(2): 48-55.

Slater J., Willis P., Gurtner W., Beutler G., Noll C., Hein G.W., Neilan R.E. (1998). The International GLONASS Experiment (IGEX-98), 11th Int. Tech. Meeting of the Satellite Division of the U.S. Inst. of Navigation GPS ION'98, Nashville, Tennessee, 15-18 Sept., 1637-1643.

Völksen Ch. (2006). Report on the Symposium of the IAG Sub-commission for Europe (EUREF), mitteilungen des BKG, Band 38, Verlag des BKG, Frankfurt/Main, 73-78.

Wang J. (1999). Precise GPS and GLONASS satellite positioning: model formulations and performance, Artificial Satellites, Vol. 34(1), 11-25.

Wang J., Rizos Ch., Stewart M.P., Leick A. (2000). GPS and GLONASS Integration: Modelling and Ambiguity Resolution Issues, GPS Solutions, Vol. 5, 55-64. 
Weber R., Slater J.A., Franger E., Glotov V., Habrich H., Romero I., Schaer S. (2005). Precise GLONASS Orbit Determination within the IGS/IGLOS Pilot Project, Advances in Space Research, Vol. 36, 369-375.

Willis P., Beutler G., Gurtner W., Hein G.W., Neilan R.E., Noll C., Slater J. (1999). IGEX: International GLONASS experiment: scientific objectives and preparation, Advanced in Space Research, Vol 23(4), 659-663.

Wu J.T., Wu S.C., Hajj G.A., Bertiger W.I., Lichten S.M. (1993). Effects of antenna orientation on GPS carrier phase, Manuscripta Geodetica, No 18, 91-98.

Wubbena G., Schmitz M., Boettcher G., Schumann Ch. (2006). Absolute GNSS Antenna Calibration with a Robot: Repeatability of Phase Variations, Calibration of GLONASS and Determination of Carrier-to-Noise Pattern, Proceedings of the IGS Workshop: Perspectives and Visions for 2010 and beyond, 8-12 May, Darmstadt, Germany.

Zeimetz P., Kuhlman H. (2008). On the Accuracy of Absolute GNSS Antenna Calibration and the Conception of a New Anechoic Chamber, FIG Working Week 2008, Stockholm, Sweden 14-19 June.

Zarraoa N., Mai W., Sardón E., Jungstand A. (1998). Preliminary evaluation of the Russian GLONASS system as a potential geodetic tool, Journal of Geodesy, Vol. 72, 356-363.

Zhang Y., Liu J. (2002). Combined GPS/GLONASS Data Processing, Information Science, Vol. 5(4), 32-36.

Received: 2014-09-08,

Reviewed: 2014-11-25, by Changsheng Cai,

Accepted: 2014-12-01. 